
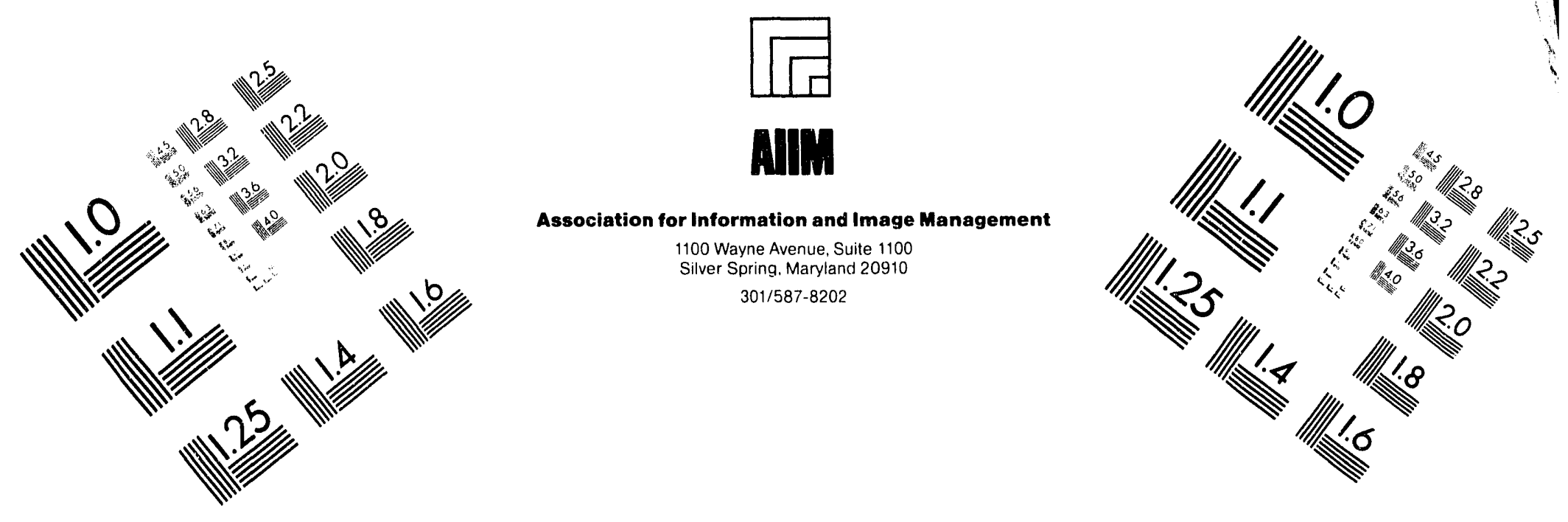

\title{
Centimeter
}

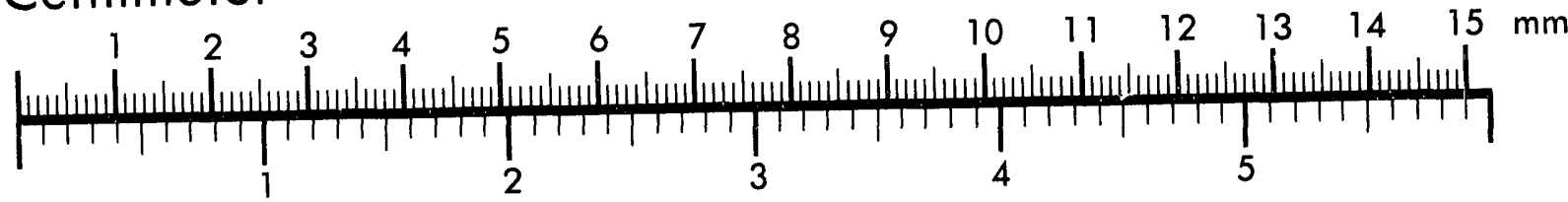
Inches
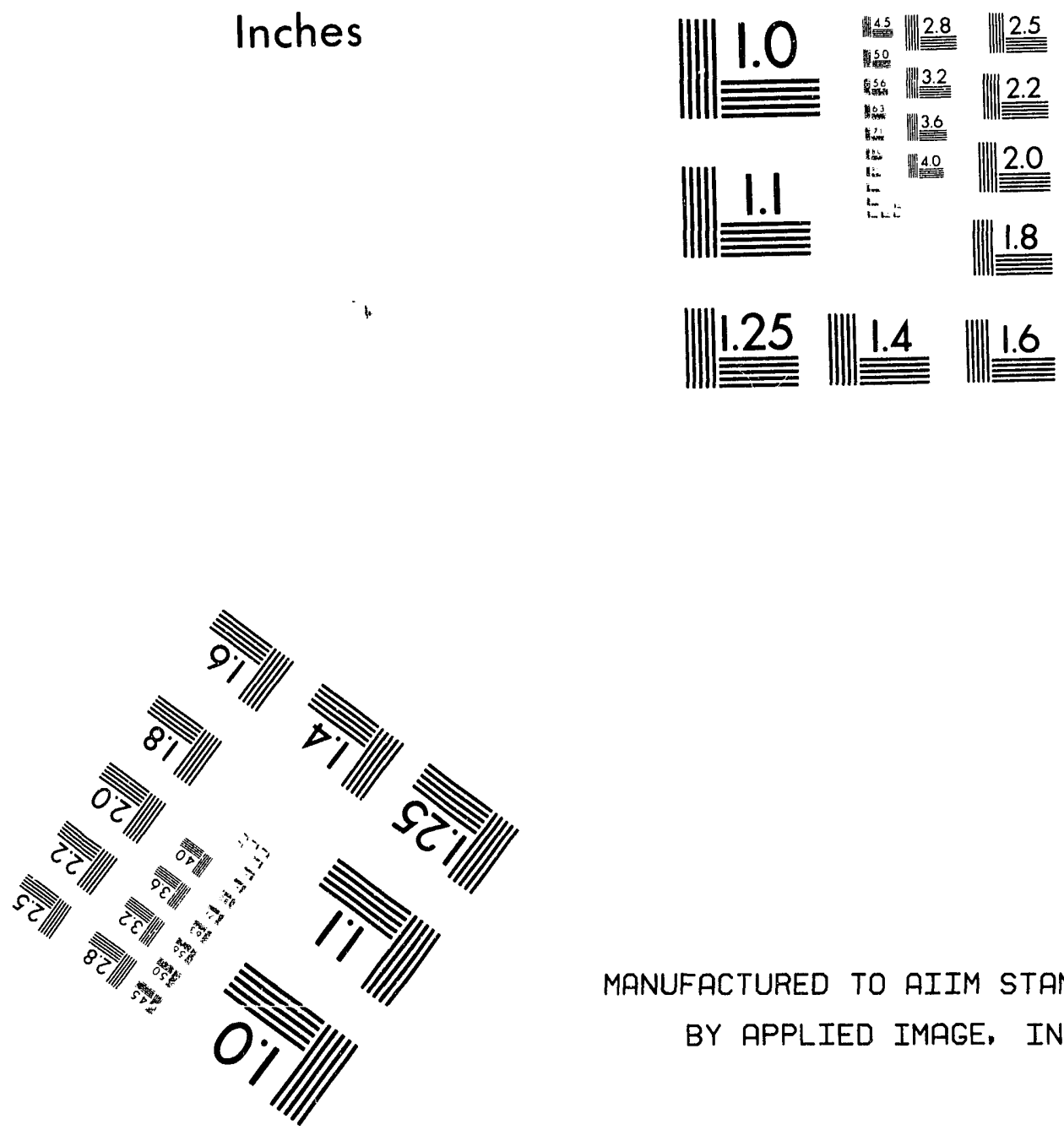

MANUFACTURED TO AIIM STANDARDS

BY APPLIED IMAGE, INC.

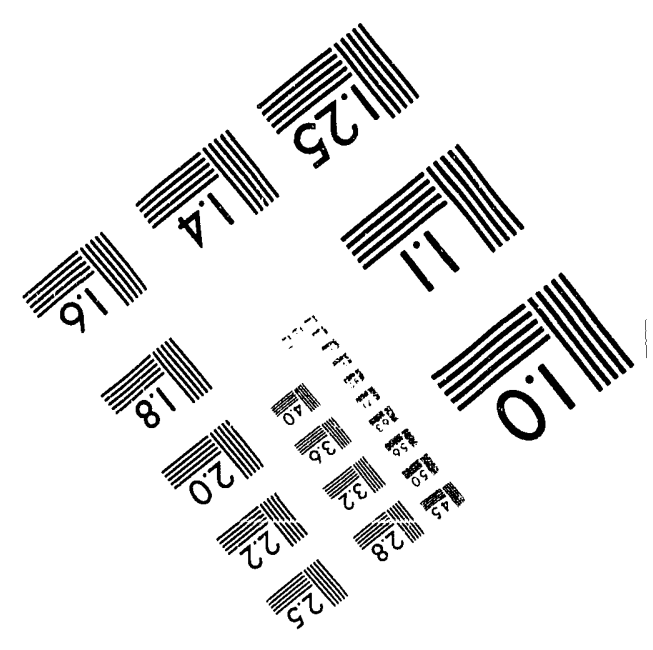



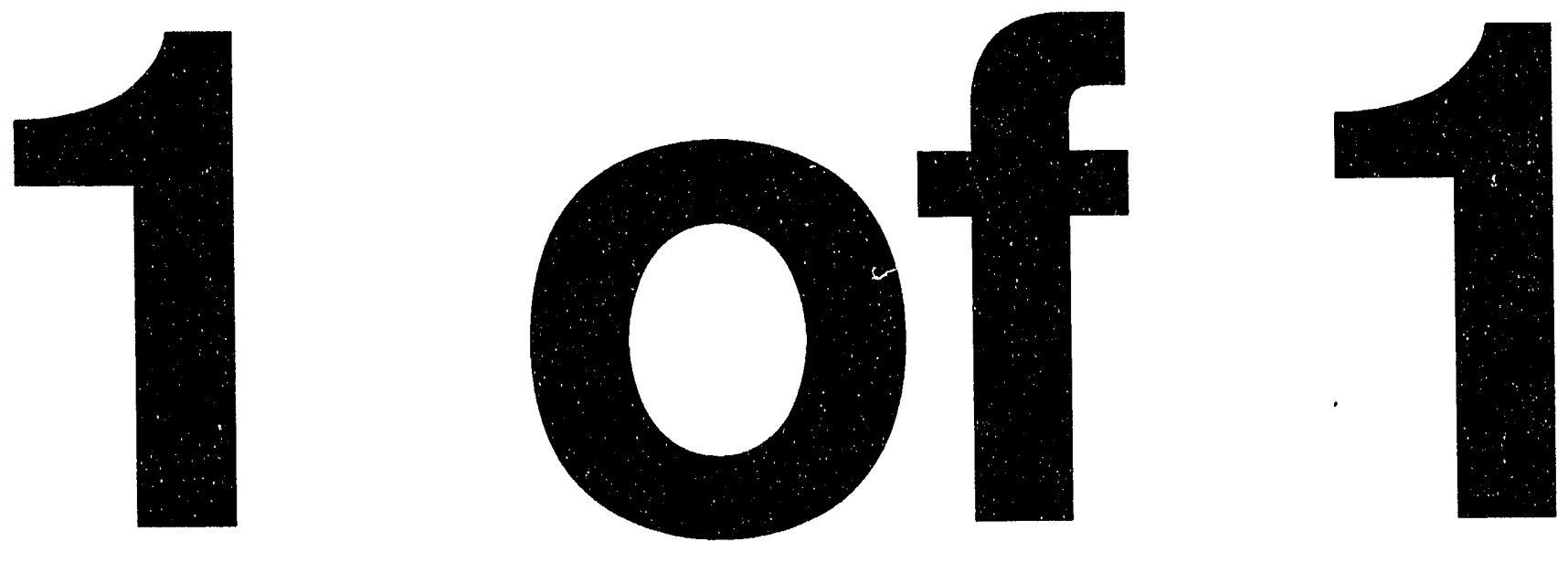
This report was prepared as an account of work sponsored by an agency of the United States Government. Neither the United States Government nor any agency thereof, nor any of their employees, makes any warranty, express or implied, or assumes any legal liability or responsibility for the accuracy, completeness, or usefuiness of any information, apparatus, product, or process disclosed, or represents that its use would not infringe privately owned rights. Reference herein to any specific commercial product, process, or service by trade name, trademark, manufacturer, or otherwise does not necessarily constitute or imply its endorsement, recommendation, or favoring by the United States Government or any agency thereof. The views and opinions of authors expressed herein do not necessarily state or reflect those of the United States Government or any agency thereof.

\title{
DAMAGE-INDUCED NONASSOCIATED INELASTIC FLOW
}

\section{IN ROCK SALT}

\section{K. S. CHAN", N. S. BRODSKY ${ }^{* *}$, A. F. FOSSUM"*, S. R. BODNER ${ }^{*+}$, AND D. E. MUNSON ${ }^{++}$}

\author{
'Southwest Research Institute, P. O. Drawer 28510, San Antonio, TX 78228-0510 \\ “RE/SPEC Inc., Rapid City, SD 57709 \\ ${ }^{++}$Sandia National Laboratories, Albuquerque, NM 87185"
}

\begin{abstract}
The multi-mechanism deformation coupled fracture model recently developed by CHAN, etal. [1992], fordescribing time-dependent, pressure-sensitive inelastic flow and damage evolution in crystalline solids was evaluated against triaxial creep experiments on rock salt. Guided by experimental observations, the kinetic equation and the flow law for damage-induced inelastic flow in the model were modified to account for the development of damage and inelastic dilatation in the transient creep regime. The revised model was then utilized to obtain the creep response and damage evolution in rock salt as a function of confining pressure and stress difference. Comparison between model calculation and experiment revealed that damage-induced inelastic flow is nonassociated, dilatational, and contributes significantly to the macroscopic strain rate observed in rock salt deformed at low confining pressures. The inelastic strain rate and volumetric strain due to damage decrease with increasing confining pressures, and all are suppressed at sufficiently high confining pressures.
\end{abstract}

Permanent address: Technion, Dept. of Mech. Eng., Haifa, Israel

"." Work supported by U.S. Department of Energy (DOE), Contract No. DE-AC04-76DP00789

A U.S. DOE facility 


\section{INTRODUCTION}

Natural salt deposits are considered desirable host rocks for permanent disposal of radioactive waste because the creep characteristics of natural salt allow closure of the disposal room, leading to eventual encapsulation of the radioactive waste and minimizing the possibility of leakage and contamination of the environment. A potential failure mode in the salt deposits is tertiary creep, which can result in time-dependent fracture in beddcd natural salt deposits (MUNSON et al [1989]). Recent concern over the potential for the development of creep-induced damage zones in the shafts and rooms excavated from bedded salt deposits has led to the need for constitutive models that are capable of describing the time-, temperature-, and pressure-dependent inelastic flow behavior of rock salt in the presence of creep-induced microcracks or cavities. This need provides the motivation for the development of two recent constitutive models (CHRISTESCU \& HUNSCHE [1992]; CHAN, BODNER, FOSSUM, \& MUNSON [1992]) that are formulated for describing the time-dependent inelastic response of rock salt due to both creep and damage processes.

The multi-mechanism deformation coupled fracture (MDCF) constitutive model by CHAN et al [1992], is an extension of the multi-mechanism deformation model (M-D) proposed by MUNSON \& DAWSON [1984] to include creep-induced damage in the form of microcracks and cavities. The extended model couples both creep and damage mechanisms for describing time-dependent, pressure-sensitive inelastic flow in rock salt under nonhydrostatic triaxial compression. In particular, both damage and dislocation flow processes contribute to the overall inelastic strain rate. As in the M-D model, the creep rate is essentially pressure-insensitive and incompressible, and originates from dislocation mechanisms. The damage-induced inelastic strain rate, on the other hand, is pressure-sensitive and dilatational, and is considered to arise from the opening of microcracks present in the material. A quantitative measure of damage is described in terms of the continuum damage variable, $\omega$, (KACHANOV [1958]), while the development of damage with inelastic deformation is provided through an appropriate evolution equation. The MDCF model allows prediction of the complete creep curve, including previously unmodeled tertiary creep, for rock salt subjected to nonhydrostatic triaxial compression. Extensive evaluation of the MDCF model, however, has not been possible because of the lack of creep data obtained under low confining pressures and for durations sufficient to reach the tertiary creep regime.

Two assumptions were made in the original development of the MDCF model. The first is that the development of creep-induced damage leads to the onset of tertiary creep and that creep-induced damage is not expected to be present, at least not in significant amounts, in the primary or secondary creep regimes, as observed in most metals and alloys. 
The second assumption is that the flow law is associated and derivable from a single flow potential. The objective of this aricle is to present results of an investigation that evaluates these two aspects of the MDCF model by conducting triaxial creep experiments for rock salt and by comparing experimental results with model calculations.

The article is divided into four parts. The first part describes the MDCF model and modification of the kinetic equation and the flow law for damage-induced inelastic flow. Highlights of the experimental results of WIPP salt under creep constitute the second part of the paper. In the third part, the associativity of damage-induced inelastic flow in WIPP salt will be examined. In the fourth part, the revised model will then be used to illustrate the suppression of the creep response and damage evolution in rock salt by confining pressure. Both the experimental and theoretical results will be used to demonstrate that damage-induced inelastic flow in rock salt is nonassociated and present in all three stages of the creep curve, and contributes to a significant part of the macroscopic strain rate observed in rock salt crept at low confining pressures.

\section{COUPLED CREEP-DAMAGE CONSTITUTIVE MODEL}

The MDCF model is a constitutive model that provides a continuum description of the creep response and the associated damage evolution in crystalline solids, such as rock salt. Both dislocation motion and creep-induced damage are assumed to contribute directly to the macroscopic inelastic strain rate. The generalized average kinetic equation for the coupled creep and damage-induced flow is given as (FOSSUM etal. [1988]; CHAN et al [1992])

$$
\dot{\varepsilon}_{i j}=\frac{\partial \sigma_{e q}^{c}}{\partial \sigma_{i j}} \dot{\varepsilon}_{e q}^{c}+\frac{\partial \sigma_{e q}^{\omega}}{\partial \sigma_{i j}} \dot{\varepsilon}_{e q}^{\omega}
$$

where $\sigma_{e q}^{c}, \sigma_{e q}^{\infty}, \dot{\varepsilon}_{e q}^{c}$, and $\dot{\varepsilon}_{e q}^{\infty}$ are work-conjugate equivalent stress measure and equivalent inelastic strain rates for the dislocation and damage mechanisms, respectively.

The effects of creep damage on inelastic flow are modeled in two ways in the MDCF model. The softening effect associated with the reduction of effective load-bearing area due to damage is modeled using the continuum damage mechanics approach. The Kachanov damage variable, $\omega$, is used as a measure of the damage level with the development of damage during deformation represented by an evolution equation (KACHANOV [1958]). Furthermore, damage also directly contributes to the inelastic strain rate through the opening of microcracks and microvoids (WALSH \& BRACE [1966]; HUTCHINSON [1983]; [HORII \& NEMAT-NASSER [1985]; HANSEN \& FOSSUM [1986]). 
This is modeled in the MDCF model in terms of an additional kinetic equation that is independent of that for dislocation mechanisms. Details of the work-conjugate stress measures, kinetic equations, the flow law, and the evolution equation for damage in the MDCF model are summarized as follows. Note that compression is taken to be positive in this paper.

\section{Work-Conjugate Equivalent Stress Measures}

The work-conjugate equivalent stress measure, $\sigma_{e q}$, for dislocation-induced flow is the Tresca stress,

$$
\sigma_{e q}^{c}=\left|\sigma_{1}-\sigma_{3}\right|
$$

where $\sigma_{1}$ and $\sigma_{3}$ are the maximum and minimum principal stresses, respectively. The Tresca stress measure is preferred over von Mises' because experimental measurements of flow surface and inelastic strain rate vectors are in better agreement with the former formulation (MUNSON, etal [1989]).

The work-conjugate equivalent stress measure for damage-induced flow is assumed to consist of three terms as represented by (CHAN, et al. [1992])

$$
\sigma_{e q}^{\omega}=\left|\sigma_{1}-\sigma_{3}\right|-x_{2} x_{7} \operatorname{sgn}\left(I_{1}-\sigma_{1}\right)\left[\frac{I_{1}-\sigma_{1}}{3 x_{7} \operatorname{sgn}\left(I_{1}-\sigma_{1}\right)}\right]^{x_{6}}-x_{1} \sigma_{3} H\left(-\sigma_{3}\right)
$$

where $I_{1}$ is the first invariant of Cauchy stress, the $x_{1}$ 's are material constants, and $H()$ denotes the Heaviside step function. The first term represents the driving force for shear-induced damage, which manifests as slip-induced microcracks with "wing-tips" or grain boundary cracks whose opening leads to irreversible inelastic strain additional to those originating from dislocation mechanisms. The third term represents the opening of microcracks by the maximum tensile stress, $\sigma_{3}$. The second term in Eq. (3), which is in the form of $f\left(I_{1}-\sigma_{1}\right)$, represents the suppression of the opening of microcracks by a confining pressure.

\section{Kinetic Equation for Dislocation Flow}

The kinetic equation representing the creep rate, $\dot{\varepsilon}_{e q}^{c}$, due to dislocation mechanisms is based on the M-D model. In this formulation, the inelastic strain rate is given by (MUNSON \& DAWSON [1984])

$$
\dot{\varepsilon}_{e q}^{c}=F \dot{\varepsilon}_{s}
$$


where $F$ is the transient function representing transient creep behavior, and $\dot{\varepsilon}_{s}$, the overall steady-state strain rate, is the sum of individual steady-state strain rates, $\dot{\varepsilon}_{v_{i}}$, for three independent dislocation mechanisms. The steady-state strain rates of the individual mechanisms, each of which is taken to be thermally activated, are (MUNSON [1979]; MUNSON \& DAWSON, [1984])

$$
\begin{gathered}
\dot{\varepsilon}_{s_{1}}=A_{1} e^{-Q_{1} / R T}\left(\frac{\sigma}{\mu(1-\omega)}\right)^{n_{1}} \\
\dot{\varepsilon}_{s_{2}}=A_{2} e^{-Q_{2} / R T}\left(\frac{\sigma}{\mu(1-\omega)}\right)^{n_{2}} \\
\dot{\varepsilon}_{s_{3}}=|H|\left(B_{1} e^{-Q_{1} / R T}+B_{2} e^{-Q_{2} / R T}\right) \sinh \left[\frac{q\left(\frac{\sigma}{(1-\omega)}-\sigma_{0}\right)}{\mu}\right]
\end{gathered}
$$

where the A's and B's are constants; $Q_{j}^{\prime}$ 's are activation energies; $T$ is the absolute temperature; $R$ is the universal gas constant; $\sigma$ is the generalized stress, taken as the stress difference, $\mu$ is the shear modulus; $n_{i}$ 's are the stress exponents; $\mathrm{q}$ is the stress constant; and $\sigma_{0}$ is the stress limit of the dislocation slip mechanism. The dislocation climb mechanism, designated by subscript 1 , dominates at low stress and high temperature. The undefined mechanism, designated by subscript 2 , dominates at low stress and temperature, and the glide mechanism, denoted by subscript 3 , controls at high stress for all temperatures. The 1- $\omega$ term in Eqs. (5)-(7) represents the reduction in the effective loading-bearing area due to the presence of damage.

The transient function, F, (MUNSON, FOSSUM, \& SENSENY [1989]) is

$$
F=\left\{\begin{array}{cc}
\exp \left[\Delta\left(1-\frac{\zeta}{\varepsilon_{t}^{*}}\right)^{2}\right] & , \zeta \leq \varepsilon_{t}^{*} \\
1 & , \zeta=\varepsilon_{t}^{*} \\
\exp \left[-\delta\left(1-\frac{\zeta}{\varepsilon_{t}^{*}}\right)^{2}\right] & , \delta \geq \varepsilon_{t}^{*}
\end{array}\right.
$$


which is composed of a work-hardening branch, an equilibrium branch, and a recovery branch. In Eq. (8), $\Delta$ and $\delta$ represent the work-hardening and recovery parameters, respectively, and $\varepsilon_{1}^{*}$ is the transient strain limit. The temperature and stress dependence of the transient strain limit is represented by (MUNSON, FOSSUM, \& SENSENY [1S89]),

$$
\varepsilon_{t}^{*}=K_{o} e^{c T}\left(\frac{\sigma}{\mu(1-\omega)}\right)^{m}
$$

where $K_{o}, c$, and $m$ are constants. The evolution rate, $\zeta$, of the intemal variable $\zeta$ is governed by

$$
\dot{\zeta}=(F-1)\left(\dot{\varepsilon}_{s}\right)
$$

which diminishes to zero when the steady-state condition is achieved.

\section{Kinetic Equation for Damage-Induced Flow}

The kinetic equation for damage-induced inelastic flow originally proposed in the MDCF model was (CHAN etal, [1992])

$$
\dot{\varepsilon}_{e q}^{\omega}=c_{1} \omega\left[\sinh \left(\frac{c_{2} \sigma_{e q}^{\omega} H\left(\sigma_{e q}^{\omega}\right)}{(1-\omega) \mu}\right)\right]^{n_{3}}
$$

where $c_{1}, c_{2}$, and $n_{3}$ are material constants. Eq. (11) shows a linear relation between $\sigma_{\iota q}^{\circ 0}$ and $\omega$ aside from the modifying factor $(1-\omega)$ on the stress. The form of Eq. (11) was selected based on theoretical results of HUTCHINSON [1983] that indicate that the inelastic strain rate due to microcracks depends linearly on the microcrack density for a dilute concentration of constrained microcracks. Because of the linear relation, damage growth leads immediately to tertiary creep.

Two discrepancies exist between Eq. (11) and the creep damage process observed in WIPP salt: (1) creep damage accumulates in the transient creep region, but does not lead to tertiary creep immediately, and (2) damage-induced inelastic strain rate exhibits a transient behavior similar to dislocation-induced creep. To account for the damage behavior observed in WIPP salt, Eq. (11) has been modified and is given by the expression as follows: 


$$
\dot{\varepsilon}_{e q}^{\omega}=F \dot{\varepsilon}_{s}^{\omega}
$$

where

$$
\dot{\varepsilon}_{s}^{\omega}=c_{1} \omega_{o} e^{c_{3} \omega}\left[\sinh \left(\frac{c_{2} \sigma_{e q}^{\omega} H\left(\sigma_{e q}^{\omega}\right)}{(1-\omega) \mu}\right)\right]^{n_{3}}
$$

with

$$
c_{1}=c_{o}\left(B_{1} e^{\left(-Q_{1} / R T\right)}+B_{2} e^{\left(-Q_{2} / R T\right)}\right) \exp \left[c_{4}\left(\frac{\sigma-c_{5}}{\sigma_{0}}\right)\right]
$$

and $c_{0}, c_{2}, c_{3}, c_{4}, c_{5}$, and $n_{3}$ are material constants; $\omega_{0}$ is the initial value of the damage variable, $\omega$. The B's and Q's are constants in dislocation glide mechanisms. This particular form of kinetic equation allows $\dot{\varepsilon}_{e q}^{\infty}$ to exhibit a transient behavior by virtue of the transient function, $F$. The form of $\dot{\varepsilon}_{,}^{\infty}$ is formulated such that it remains fairly constant for small values of $\omega$ so that tertiary creep is not prematurely activated. A potential drawback of Eq. (12) is that $\dot{\varepsilon}_{e q}^{\infty}$ is sensitive to $\omega_{0}$. On the other hand, Eq. (13) draws attention to the importance of the initial damage on the inelastic flow behavior of WIPP salt.

Damage development is described by the damage evolution equation (BODNER [1985]; BODNER \& CHAN [1986]; CHAN etal. [1992])

$$
\dot{\omega}=\frac{x_{4}}{x_{5}} \omega\left[\ln \left(\frac{1}{\omega}\right)\right]^{\frac{x_{4}+1}{x_{4}}}\left[\sigma_{e q}^{\omega} H\left(\sigma_{e q}^{\omega}\right)\right]^{x_{3}}-h\left(\omega, T, I_{1}\right)
$$

where $x_{3}, x_{4}$, and $x_{5}$ are material constants, and $h\left(\omega, T, I_{1}\right)$ is the damage healing function whose form remains to be determined. The damage healing term $h\left(\omega, T, I_{1}\right)$, is expected to depend on the damage variable, $\omega$, temperature, $T$, and confining pressure, $P$.

\section{Flow Law}

In the MDCF model, inelastic flow was originally assumed to be associated for both dislocation and damage mechanisms. The associated flow law was obtained by taking the stress derivative of the work-conjugate equivalent stress measures shown in Eqs. (2) and (3) and substituting the results into Eq. (1), leading to 


$$
\dot{\varepsilon}_{i j}=\left(\dot{\varepsilon}_{e q}^{c}+\dot{\varepsilon}_{e q}^{\omega}\right)\left[b_{1} s_{i j}+b_{2} t_{i j}\right]-\dot{\varepsilon}_{e q}^{\omega}\left[b_{4}\left(\delta_{i j}-m_{i j}\right)+b_{5} m_{i j}\right]
$$

where

$$
s_{i j}=\sigma_{i j}-\frac{1}{3} \sigma_{k k} \delta_{i j}
$$

is the stress deviator, $\delta_{i j}$ is the Kronecker delta, and

$$
t_{i j}=s_{i k} s_{k j}-\frac{2}{3} J_{2} \delta_{i j}
$$

is the deviator of the square of the deviatoric stress. The coefficients in Eq. (16) are given by,

$$
\begin{gathered}
b_{1}=\frac{\cos (2 \Psi)}{\sqrt{J_{2}} \cos (3 \Psi)} \\
b_{2}=\frac{\sqrt{3}}{J_{2}} \frac{\sin \Psi}{\cos (3 \Psi)} \\
b_{4}=\frac{x_{2} x_{6}}{3}\left[\frac{I_{1}-\sigma_{1}}{3 \operatorname{sgn}\left(I_{1}-\sigma_{1}\right)}\right]^{x_{6}-1} \\
b_{5}=x_{1} H\left(-\sigma_{3}\right)
\end{gathered}
$$

where $\Psi$ is the Lode angle, $J_{2}$ is the second invariant of the deviatoric stress, and $m_{i j}=d \sigma_{1} / d \sigma_{i j}$ are given in an earlier paper (CHAN eLal. [1992]).

Instead of associativity, it is also possible that damage-induced inelastic flow is nonassociated. To examine this possibility, a different work-conjugate equivalent stress measure, $\sigma_{e q}^{\infty}$, is assumed and used in conjunction with Eq. (1) to obtain the flow law for damage-induced inelastic flow. The proposed function for $\sigma_{e q}^{\infty \pi}$ is

$$
\sigma_{e q}^{\omega}=\left|\sigma_{1}-\sigma_{3}\right|-\frac{x_{2} x_{8}}{3}\left[I_{1}-\sigma_{1}\right]-x_{1} \sigma_{3} H\left(-\sigma_{3}\right)
$$


which leads to the same flow law as described in Eq. (16), but with

$$
b_{4}=x_{2} x_{8}
$$

where $x_{8}$ is a material constant, while $b_{1}, b_{2}$, and $b_{5}$ are given in Eqs. (19), (20), and (21).

\section{TRLAXIAL CREEP EXPERIMENTS}

Complete experimental creep curves, including tertiary creep, are available, and even though the data base is not extensive, these curves can be analyzed through the MDCF model for axial, lateral, and volumetric straius. In these tests, conventional triaxial compression creep experiments were conducted at a constant stress difference of $25 \mathrm{MPa}$ with various values of confining pressure $(\mathrm{P})$, ranging from 0.5 to $15 \mathrm{MPa}$. The testing technique, specimen characterization, and preliminary evaluation of the axial strain have already been given by FOSSUM et al [1993]. These test results will be summarized as background for use here in a more complete analysis based on the modified MDCF model.

The axial, lateral, and volumetric strains were measured as a function of time of creep. Fig. 1 shows the axial and volumetric strains observed in WIPP salt tested at a stress difference of $25 \mathrm{MPa}$ for confining pressures of 1 and $15 \mathrm{MPa}$. Similar creep curves for the same stress difference but for confining pressures of 2 and $3.5 \mathrm{MPa}$ are shown in Fig. 2. The influence of the confining pressure on the creep response is evident. As shown in Fig. 1, deformation occurred more readily at a confining pressure of $1 \mathrm{MPa}$ than at $15 \mathrm{MPa}$. Tertiary creep and volumetric strain were evident at $1 \mathrm{MPa}$ pressure, but not at $15 \mathrm{MPa}$ pressure. Another important observation in Fig. 1 is that creep damage, as measured by the volumetric strain, developed early in the primary creep regime and accumulated throughout all three stages (primary, secondary, and tertiary) of creep in WIPP salt tested at 1 MPa. Similar observations were made on the results shown in Fig. 2.

The value of the minimum strain rate, $\dot{\varepsilon}_{\mathrm{man}}$, observed in WIPP salt crept at a stress difference of $25 \mathrm{MPa}$ was not a constant, but decreased with increasing confining pressures, as snown in Fig. 3. Specifically, the minimum strain rate was reduced significantly by a small increase in the confining pressure at low pressure levels (0.5-3.5 $\mathrm{MPa})$. At higher confining pressures (3.5-15 MPa), the minimum strain rates were essentially independent of the confining pressure, Fig. 3. The decrease in the minimum strain rate also corresponded to decrease in the volumetric strain with increasing confining pressure, Fig. 4 . The experimental evidence suggested that creep damage contributed to a higher deformation rate in WIPP salt at low confining pressures. Additionally, the damage-induced inelastic flow was reduced when creep damage was suppressed by a higher confining pressure. At a sufficienlly high confining pressure, creep 
damage was totally suppressed and the minimum strain rate corresponded to the creep rate due to dislocation motion only, whose value is essentially independent of the confining pressure. Thus, the apparent strong influence of pressure on the triaxial creep response of WIPP salt at low confining pressure appears to be a manifestation of the suppression of damage-induced inelastic flow by a confining pressure.

\section{NONASSOCIATIVITY OF DAMAGE-INDUCED INELASTIC FLOW}

The question concerning the associativity of damage-induced flow was examined by comparing model calculations against experimental data of axial, lateral, and volumetric strains for creep of WIPP salt at low confining pressures. Material constants for WIPP salt are summarized in Table 1. Model constants related to dislocation mechanisms (M-D model) were determined previously using creep data obtained at a confining pressure of $15 \mathrm{MPa}$ (MUNSON et al. [1989]). The same set of material constants was used and is shown at the left column in Table 1. Additional material constants related to damage-induced flow and damage evolution are shown in the right column of Table 1. They were determined by fitting the model to the creep curves of WIPP salt at low confining pressures, (e.g., $1 \mathrm{MPa}$ ) or by assuming values thought to be physically realistic.

Note that in Table 1, two values of $x_{6}$ are reported; $x_{6}=1$ for $P<1.5 \mathrm{MPa}$, and $x_{6}>1.5 \mathrm{MPa}$. The pressure dependence of damage-induced inelastic flow was nonlinear for WIPP salt; hence, $x_{6}=0.65$. However, the $b_{4}$ term in the associated law (Eq. 21 ) becomes singular at zero confining pressure $(P=0)$ when $x_{6}<1$. As a result, $x_{6}$ was taken to be 1 for $\mathrm{P}<1.5 \mathrm{MPa}$, and $\mathrm{x}_{6}=0.65$ for $\mathrm{P}>1.5 \mathrm{MPa}$. This restriction on $\mathrm{x}_{6}$ does not apply in the $\mathrm{b}_{4}$ term for the ronassociated flow law (Eq. 24). However, in order to make a one-to-one comparison, the same set of $x_{6}$ values was used for both flow laws. For the nonassociated flow law, $x_{8}=0.1$. All other constants were identical for both formulations.

Fig. 5 shows comparison of calculated and measured creep curves for WIPP salt tested at $25^{\circ} \mathrm{C}$ subjected to $\sigma_{1}-\sigma_{3}=25 \mathrm{MPa}$ and $\mathrm{P}=1 \mathrm{MPa}$, while Fig. 6 presents results for the lateral and volumetric strains. Model calculations were performed based on the associated flow law. Despite the good agreement obtained for the axial strain (Fig. 5), large discrepancies were observed for the lateral and volumetric strains (Fig. 6). The overpredictions by the associated flow formulation indicated that damage-induced inelastic flow in WIPP salt was nonassociated. This notion was supported by the results shown in Fig. 7, which shows that calculated lateral and volumetric strains based on the nonassociated flow formulation are in good agreement with experimental data. 


\section{PRESSURE DEPENDENCE OF DAMAGE-INDUCED INELASTIC FLOW}

Comparison of model calculations and experimental results for axial and volumetric strains is shown in Fig. 1 for confining pressures of 1 and $15 \mathrm{MPa}$, with corresponding values for the damage variable, $\omega$, shown in Fig. 8 . When comparing calculational results based on average parameter values, it should be noted that individual creep curves may show an experimental scatter of about a factor of 2.5 for identical test conditions. Figs. 1 and 8 illustrate that damage accumulation at $1 \mathrm{MPa}$ leads to (1) a higher deformation rate (damage-induced inelastic strain rate) in the transient creep regime, (2) an inelastic dilatational strain in the transient creep regime, and (3) tertiary creep. At $15 \mathrm{MPa}$ confining pressure, creep damage was suppressed as $\omega=0$, tertiary creep was absent, and the corresponding volumetric strain was nil. Thus, the inelastic flow behavior of WIPP salt is dilatational at $P=1 \mathrm{MPa}$ due to damage accumulation, but is incompressible at $\mathrm{P}=15 \mathrm{MPa}$ when damage is totally suppressed. Comparison of model calculations and experimental results for confining pressures of 2 and $3.5 \mathrm{MPa}$ is shown in Fig. 2. At these intermediate pressure levels, dilatational flow was present, but its magnitude was reduced.

The various inelastic strain rate components that constitute the calculated inelastic strain rate, $\dot{\varepsilon}$, for creep of WIPP salt at $1 \mathrm{MPa}$ pressure are shown in Fig. 9 as a function of the damage variable, $\omega$. In Fig. 9, the curve labelled as $\dot{\varepsilon}_{e q}^{\infty}$ was calculated via Eq. (12), with $\dot{\varepsilon}_{s}^{\infty}$ given by Eq. (13); the former represents the inelastic strain rate induced by creep damage. The creep rate due to dislocation motion is shown as $\dot{\varepsilon}_{e q}^{c}$, while $\dot{\varepsilon}$ is the sum of $\dot{\varepsilon}_{e q}^{\infty}$ and $\dot{\varepsilon}_{e q}^{c}$. The value of $\dot{\varepsilon}_{s}^{\omega}$ is essentially constant at low values of $\omega$, but increases rapidly when $\omega$ exceeds 0.02 .

Three important observations were made of the results shown in Fig. 9. First, $\dot{\varepsilon}_{e q}^{\infty}$ was a significant part of $\dot{\varepsilon}$. Second, $\dot{\varepsilon}_{e q}^{\oplus}$ was greater than $\dot{\varepsilon}_{e q}^{c}$ over the whole range of damage values (or equivalently, the time of creep) examined. Third, the initial decreases of $\dot{\varepsilon}, \dot{\varepsilon}_{e q}^{\infty}$, and $\dot{\varepsilon}_{e q}^{c}$ at low values of the damage variable, $\omega$, were due to reduction in the value of the transient function, F, with time of creep (or damage), which is presented in Fig. 10. The value for the transient function, $F$, at the minimum strain rate was $\approx 4$, compared to 1 for steady state creep. Based on these results, it is evident that damage-induced inelastic flow dominates, or contributes significantly to, the deformation response of WIPP salt at low confining pressures, and this domination begins in the primary creep region. As damage accumulates, tertiary creep is initiated without the presence of a true steady-state creep, as evidenced by the relatively large value for $F$ when the minimum value of $\dot{\varepsilon}$ was observed. In the presence of damage, the minimum strain rate does not correspond to true steady state creep, but it is formed as the consequence of termination of transient creep by the onset of tertiary creep due to damage. 
The minimum strain rates corresponding to the "secondary' regime of the calculated and experimental creep curves are presented in Fig. 3, which show that for both cases, the minimum creep rate increases rapidly with decreasing confining pressures for pressures less than approximately $5 \mathrm{MPa}$. This increase in the minimum strain rate is due to the contribulion of damage-induced inelastic flow. At pressures above $5 \mathrm{MPa}$, the calculated minimum strain (creep) rate is dependent weakly on the confining pressure. This weak dependence, which arises from the dependence of diffusion on confining pressure, was modeled using the relation (FROST \& ASHBY [1982])

$$
\dot{\varepsilon}=\dot{\varepsilon}_{o} \exp \left[-\left(P-P_{o}\right) V^{*} / k T\right]
$$

where $P_{0}$ and $\dot{\varepsilon}_{o}$ are the reference pressure (15 MPa) and the creep rate at $P_{o}$, respectively; $V^{*}$ is the activation volume for diffusion, and $k$ is the Boltzmann's constant. For rock salt, $V^{*}=8.53 \times 10^{-29} \mathrm{~m}^{3}$ (FROST \& ASFIBY [1982]). Since dislocation climb is generally considered to be controlled by diffusion, Eq. (23) was applied to the two climb mechanisms in the M-D model, but not to the dislocation glide mechanism. For the pressure levels examined, the effect of pressure on the activation volume is negligible and smaller than the experimental scatter. However, this pressure effect is included in the model salculations for the sake of completeness.

Comparison of the calculated and measured inelastic volumetric strains for various confining pressures is presented in Fig. 4. The volumetric strain values reported in Figure 4 represent the volume strains at the time when the creep strain rate reaches its minimum value. The calculated inelastic volumetric strain is largest at $P \approx 0.5 \mathrm{MPa}$, and it decreases with increasing pressures. At confining pressures above $\approx 5 \mathrm{MPa}$, the inelastic volumetric strain is zero due to suppression of damage by confining pressure. The calculated results are in fair agreement with experimental data, Fig. 4. Thus, pressure-sensitive flow in WIPP salt at low confining pressures is the consequence of creep damage contributing directly to the macroscopic inelastic strain. Suppression of creep damage by a high confining pressure elimina es damage-induced flow and inelastic dilatation.

\section{CONCLUSIONS}

1. Damar ?-induced inelastic strain rate, which constitutes a significant portion of the macroscopic strain rate, commences in the transient regime and accumulates throughout the three regimes of creep in WIPP salt tested at low confining pressures.

2. The direct contribution of creep damage to the mactoscopic inelastic strain rate may be modeled in terms of a kinetic equation that relates the damage-induced inelastic strain rate to the damage variable and the work-conjugate equivalent stress measure. 
3. Damage-induced inelastic flow in WIPP salt is nonassociated, dilatational, and pressure-dependent. Because of nonassociativity, two different work-conjugate equivalent stress measures are required in the kinetic equation and the flow law.

4. Pressure-dependent creep in WIPP salt at low confining pressures is the consequence of damage contributing directly to the macroscopic inelastic strain rate. Suppression of creep damage by a high confining pressure leads to elimination of damage-induced inelastic flow, plastic dilatation, and eventually to pressure-independent flow characteristics of the dislocation mechanisms.

5. The MDCF model has been modified to account for damage accumulation in the transient creep regime and for nonassociativity in the inelastic flow due to damage. The modified model is capable of representing the creep response of WIPP salt both at low and high confining pressures.

\section{ACKNOWLEDGEMENT}

The clerical assistance of Ms. Julie McCombs and Ms. Terry Miller, Southwest Research Institute, is acknowledged.

\section{REFERENCES}

1958 KACHANOV, L. M., Izv. Akad. Nauk, USSR, Otdgel. Tekh, Nauk., 8, 26.

1966 WALSH, J. B., and BRACE, W. F., "Elasticity of Rock: A Review of Some Recent Theoretical Studies," Rock Mechanics \& Engineering Geology, 4, 283.

1979 MUNSON, D. E., "Preliminary Deformation-Mechanism Map for Salt (With Application to WIPP)," SAND79-0076, Sandia National Laboratories, Albuquerque, NM.

1982 FROST, H. J., and ASHBY, M. F., Deformation-Mechanism Maps, Pergamon Press, Oxford, pp. 129-132.

1983 HUTCHINSON, J. W., "Constitutive Behavior and Crack Tip Fields for Materials Undergoing Creep-Constrained Grain Boundary Cavitation," Acta Met., 31, 1079.

1984 MUNSON, D. E., and DAWSON, P. R., "Salt Constitutive Modeling Using Mechanism Maps," Proc. First International Conf. on the Mechanical Behavior of Salt, Trans. Tech. Publications, Clausthal, Germany, pp. 717-737. 
BODNER, S. R., "Evaluation Equations for Anisotropic Hardening and Damage of Elastic-Viscoplastic Materials," Plasticity Today, Sawczuk, A., and Bianchi G. (ed.), Elsevier and Applied Science, London, pp. 471-482.

1985

HORII, H., and NEMAT-NASSER, S., "Compression-Induced Microcrack Growth in Brittle Solids: Axial Splitting and Shear Failure," J. of Geophysical Research, 90, 3105.

BODNER, S.R., and CHAN, K. S., "Modeling of Continuum Damage for Application in Elastic-Viscoplastic Constitutive Equations," Eng. Fract. Mech., 25, 705.

HANSEN, F. D., and FOSSUM, A. F., "Failure of Salt by Fracture," Topical Report RSI-0304, RE/SPEC Inc., Rapid City, South Dakota.

FosSUM, A. F., CALlAHAN, G. D., VAN SAMBEEK, L. L., and SENSETYY, P. "How Should One-Dimensional Laboratory Equations Be Cast into Three-Dimensional Form?" Proc. 29th Symposium on Rock Mechanics, CUNDALL, P. A., STERLING, R.L., and STARFIELD, A.M. (eds.), Balkema, Rotterdam, pp. 35-41.

MUNSON, D.E., FOSSUM, A.F., and SENSENY,P.E., "Advances in Resolution of Discrepancies Between Predicted and Measured In-situ WIPP Room Closures," SAND88-2948, Sandia National Laboratories, Albuquerque, NM.

1990 HUNSCHE, U., and ALBRECHT, H., "Results of True Triaxial Strength Tests on Rock Salt," Eng. Fract. Mech., 35, 867.

1992 CHAN, K. S., BODNER, S. R., FOSSUM, A. F., and MUNSON, D. E., "A Constitutive Model for Inelastic Flow and Damage Evolution in Solids Under Triaxial Compression," Mech. Mat., 14, 1.

1992 CHRISTESCU, N. and HUNSCHE, U., "Determination of Nonassociated Constitutive Equation for Rock Salt from Experiments," in Finite Inelastic Deformation-Theory and Application, BESDO, D., and STEIN,nE. (ed), Springer-Verlag, Berlin, pp. 511-523.

1993 FOSSUM, A. F., BRUDSKY, N. S., CHAN, K. S., and MUNSON, D. E., "Experimented Evaluation of a Constitutive Model for Inelastic Flow and Camage Evolution in Solids Subjected to Triaxial Compression," International Journal of Rock Mech. Mining Science \& Geomech. Abs. [in press]. 


\section{LIST OF FIGURES}

Figure 1. Experimental creep data of WIPP salt tested at $\sigma_{1}-\sigma_{3}=25 \mathrm{MPa}$ under a confining pressure of 1 or 15 MPa and comparison with model calculations.

Figure 2. Experimental creep data of WIPP salt tested at $\sigma_{1}-\sigma_{3}=25 \mathrm{MPa}$ inder a confining pressure of 2 or 3.5 $\mathrm{MPa}$ and comparison with model calculations.

Figure 3. Experimental and calculated minimum strain rates as a function of a confining pressure for creep of WIPP salt at $\sigma_{1}-\sigma_{3}=25 \mathrm{MPa}$. The pressure depunder ce at low confining pressure is due to contribution of damage to the macroscopic strain rate. Influence of confining pressure on the minimum strain rate is drastically reduced at high confining pressures (after FOSSUM, et al., [1993]).

Figure 4. Measured and calculated volumetric strains for creep of WIPP salt tested at $\sigma_{1}-\sigma_{3}=25 \mathrm{MPa}$ under various confining pressures. The volumetric strains were obtained at the time when the minimum strain (creep) rate was observed.

Figure 5. Comparison of calculated and experimental creep curves for WIPP salt tested at a stress difference of $25 \mathrm{MPa}$ and $1 \mathrm{MPa}$ confining pressure.

Figure 6. Comparison of calculated and experimental lateral and volumetric strains for WIPP salt crept at a stress difference of $25 \mathrm{MPa}$ and $1 \mathrm{MPa}$ confining pressure. Calculation is based on the associated flow law.

Figure 7. Comparison of calculated and experimental lateral and volumetric strains for WIPP salt crept at a stress difference of $25 \mathrm{MPa}$ and $1 \mathrm{MPa}$ confining pressure. Calculation is based on the nonassociated flow law.

Figure 8. Values of the damage variable, $\omega$, corresponding to the creep curves shown in Figure 1.

Figure 9. Comparison of the creep rate $\left(\dot{\varepsilon}_{e q}^{c}\right)$ and damaged-induced inelastic strain rate $\left(\dot{\varepsilon}_{e q}^{\oplus}\right)$ to the macroscopic strain rate $(\dot{\varepsilon})$ showing $\dot{\varepsilon}_{e q}^{\infty}$ is a significant portion of the macroscopic strain rate.

Figure 10. Values of the transient function, $F$, as a function of the damage variable. 


\section{Table 1: Material Constants for WirP (Clean) Salt}

Elastic Properties

$\begin{array}{ll}\mu & 12.4 \mathrm{GPa} \\ \text { E } & 31.0 \mathrm{GPa} \\ \text { v } & 0.25\end{array}$

M - D Model Constants

Damage Model Constants

\begin{tabular}{|c|c|c|}
\hline$A_{1}$ & $8.386 \mathrm{E} 22 \mathrm{sec}^{-1}$ & $x_{2}=10.0$ \\
\hline$Q_{1}$ & $1.045 \times 10^{5}$ & $x_{3}=5.5$ \\
\hline$n_{1}$ & 5.5 & $x_{4}=3.0$ \\
\hline \multirow[t]{5}{*}{$B_{1}$} & $6.086 \mathrm{E}^{6} \mathrm{sec}^{-1}$ & $x_{5}=1.0 \times 10^{13}(\mathrm{MPa})^{5.5}-\mathrm{sec}$ \\
\hline & & $x_{6}=1$ for $\mathrm{P}<1.5 \mathrm{MPa}$ \\
\hline & & $x_{6}=0.65$ for $\mathrm{P}>1.5 \mathrm{MPa}$ \\
\hline & & $x_{7}=1 \mathrm{MPa}$ \\
\hline & & $x_{8}=0.1$ \\
\hline$A_{2}$ & $9.672 \mathrm{E} 12 \mathrm{sec}^{-1}$ & $c_{0}=7.0 \times 10^{7}$ \\
\hline$Q_{2}$ & $4.18 \times 10^{4}$ & $c_{2}=100.0$ \\
\hline$m_{2}$ & 5.0 & $c_{3}=10.0$ \\
\hline \multirow[t]{2}{*}{$B_{2}$} & $3.034 \mathrm{E}-2 \mathrm{sec}^{-1}$ & $c_{4}=6.0$ \\
\hline & & $c_{5}=25 \mathrm{MPa}$ \\
\hline$\sigma_{0}$ & $20.57 \mathrm{MPa}$ & $n_{3}=3$ \\
\hline$q$ & $5.335 \mathrm{E} 3$ & \\
\hline$R$ & $8.3143 \mathrm{~J} / \mathrm{mol}{ }^{`} \mathrm{~K}$ & $\omega_{0}=1 \times 10^{-4}$ \\
\hline$m$ & 3.0 & \\
\hline$K_{\mathrm{o}}$ & $6.275 \mathrm{E} 5$ & \\
\hline$c$ & $0.009198 \mathrm{~K}^{-1}$ & \\
\hline$\alpha$ & -17.37 & \\
\hline$\beta$ & -7.738 & \\
\hline$\delta$ & 0.58 & \\
\hline
\end{tabular}




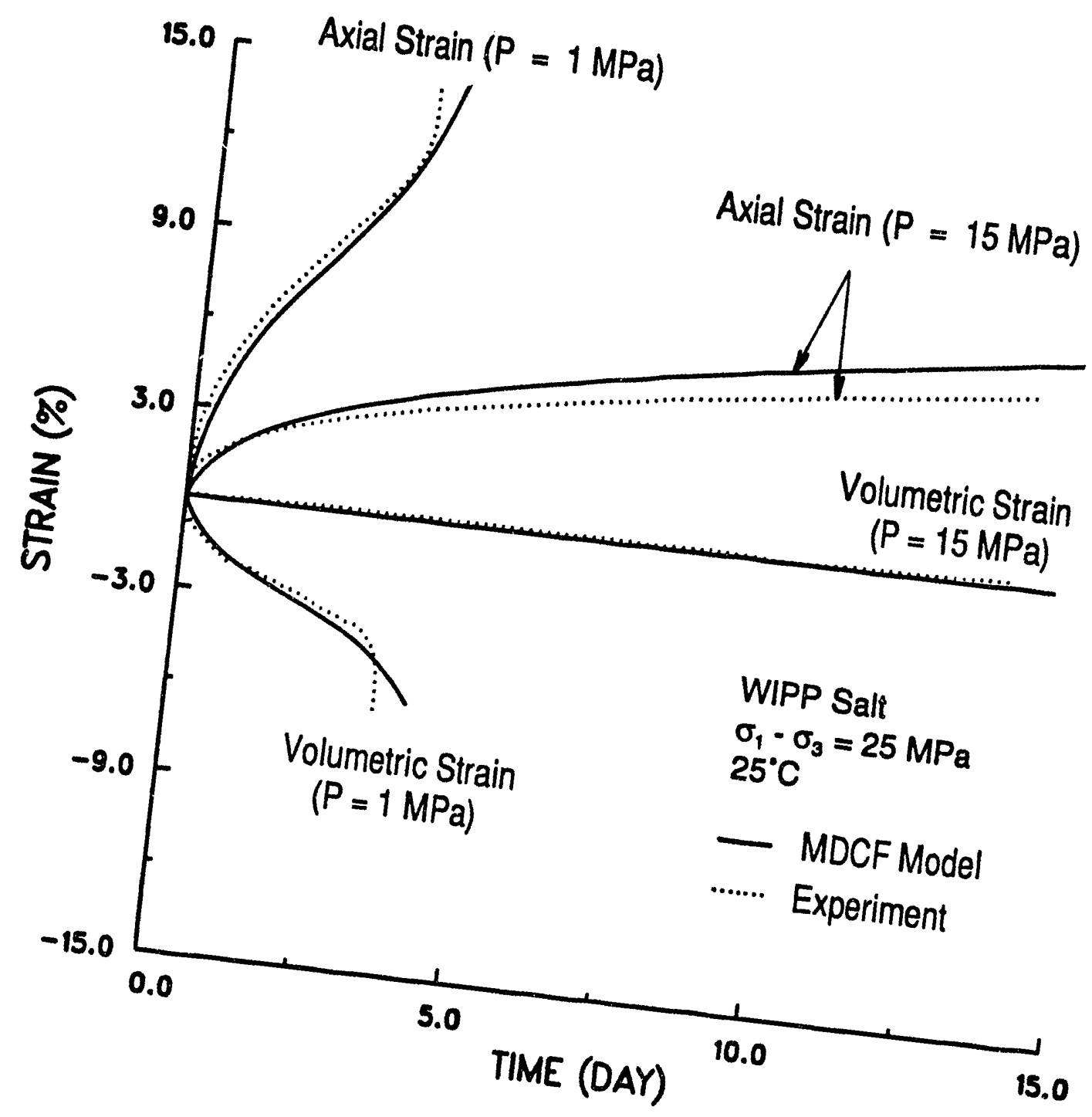

Figure 1. Experimental c pressure of 1 or $15 \mathrm{MPa}$ of WTPP 


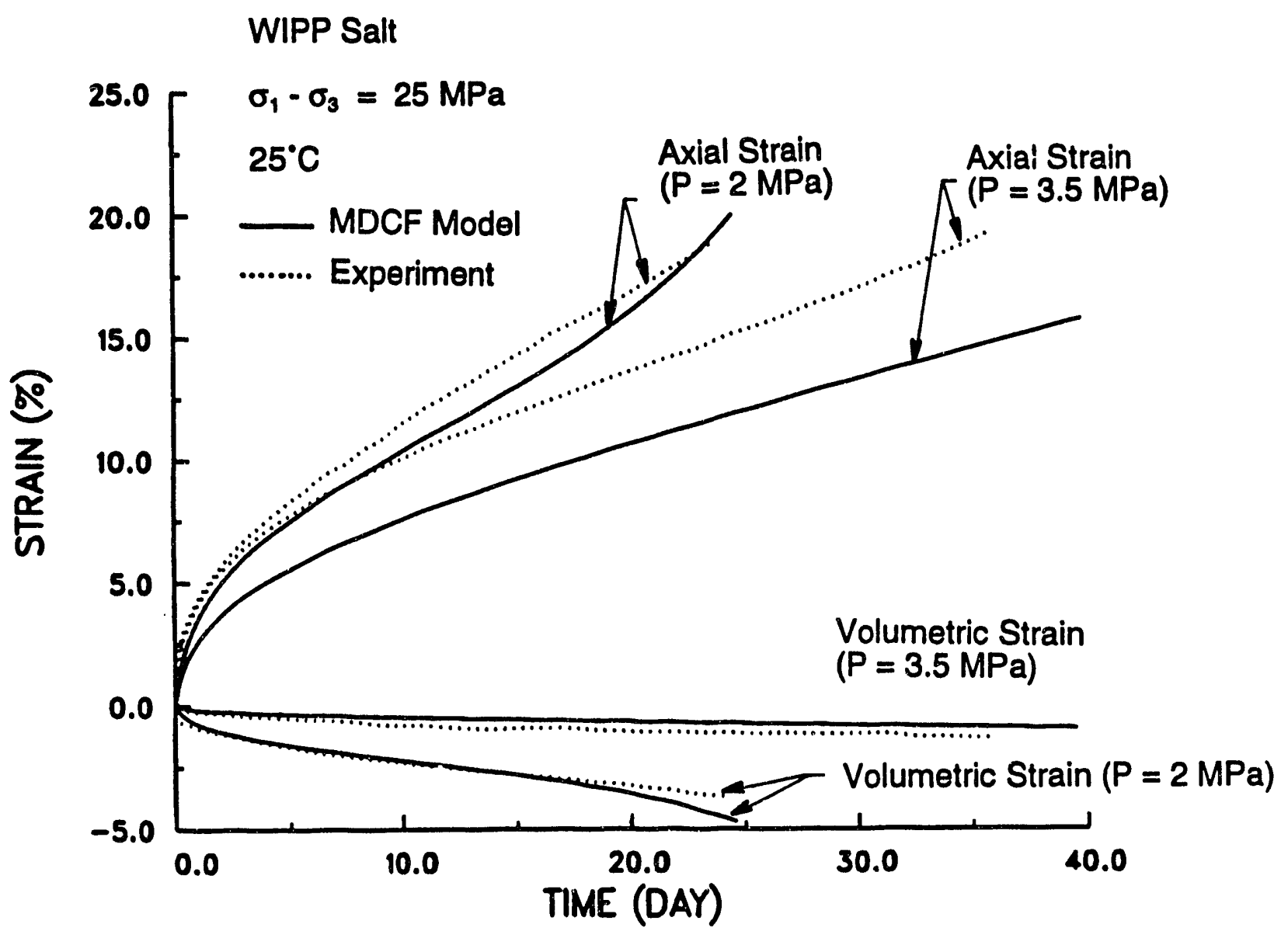

Figure 2. Experimental creep data of WIPP salt tested at $\sigma_{1}-\sigma_{3}=25 \mathrm{MPa}$ under a confining pressure of 2 or $3.5 \mathrm{MPa}$ and comparison with model calculations. 


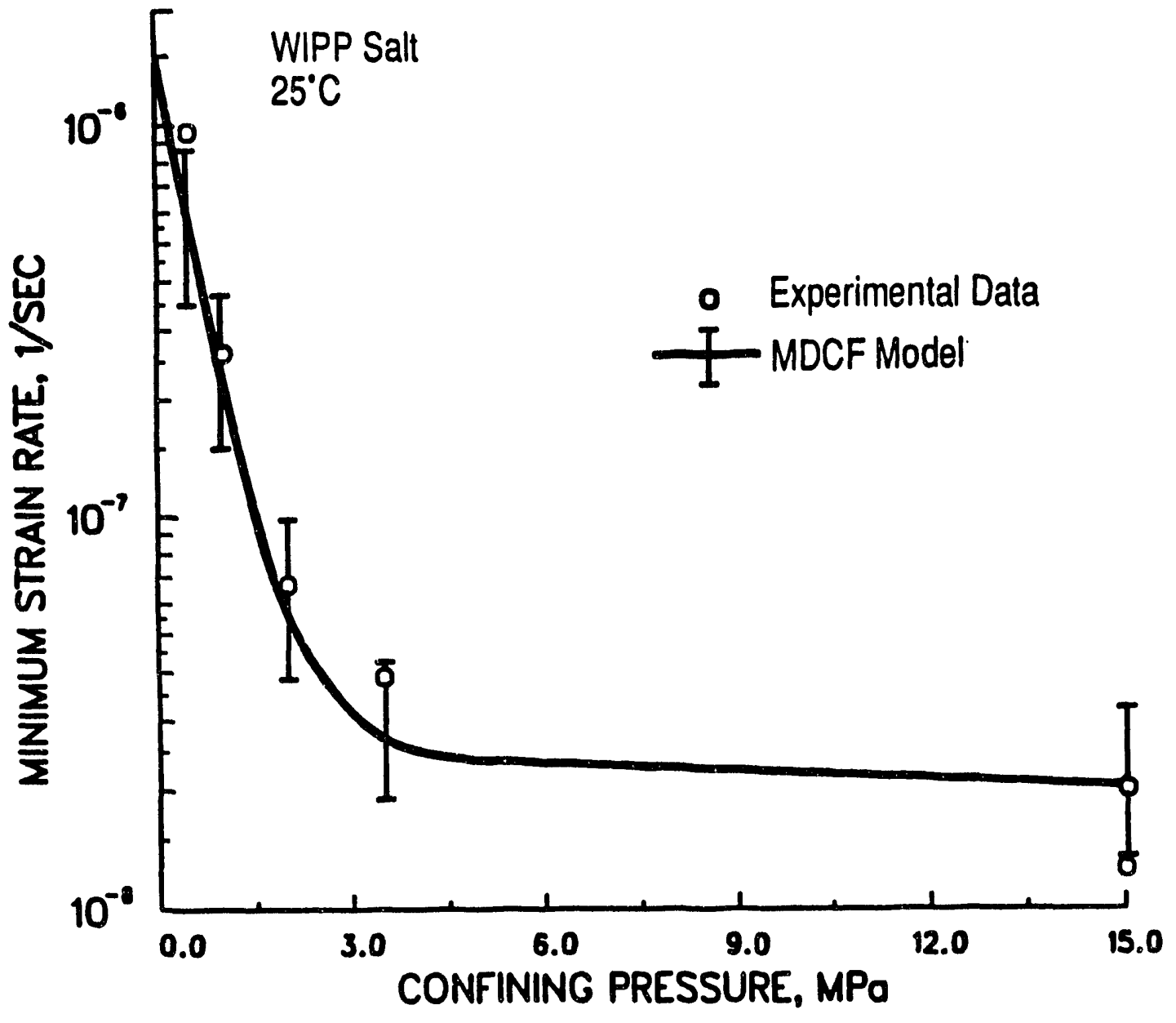

Figure 3. Experimental and calculated minimum strain rates as a function of a confining pressure for creep of WIPP salt at $\sigma_{1}-\sigma_{3}=25 \mathrm{MPa}$. The pressure dependence at low confining pressure is due to contribution of damage to the macroscopic strain rate. Influence of confining pressure on the minimum strain rate is drastically reduced at high confining pressures (after FOSSUM, et al., [1993]). 


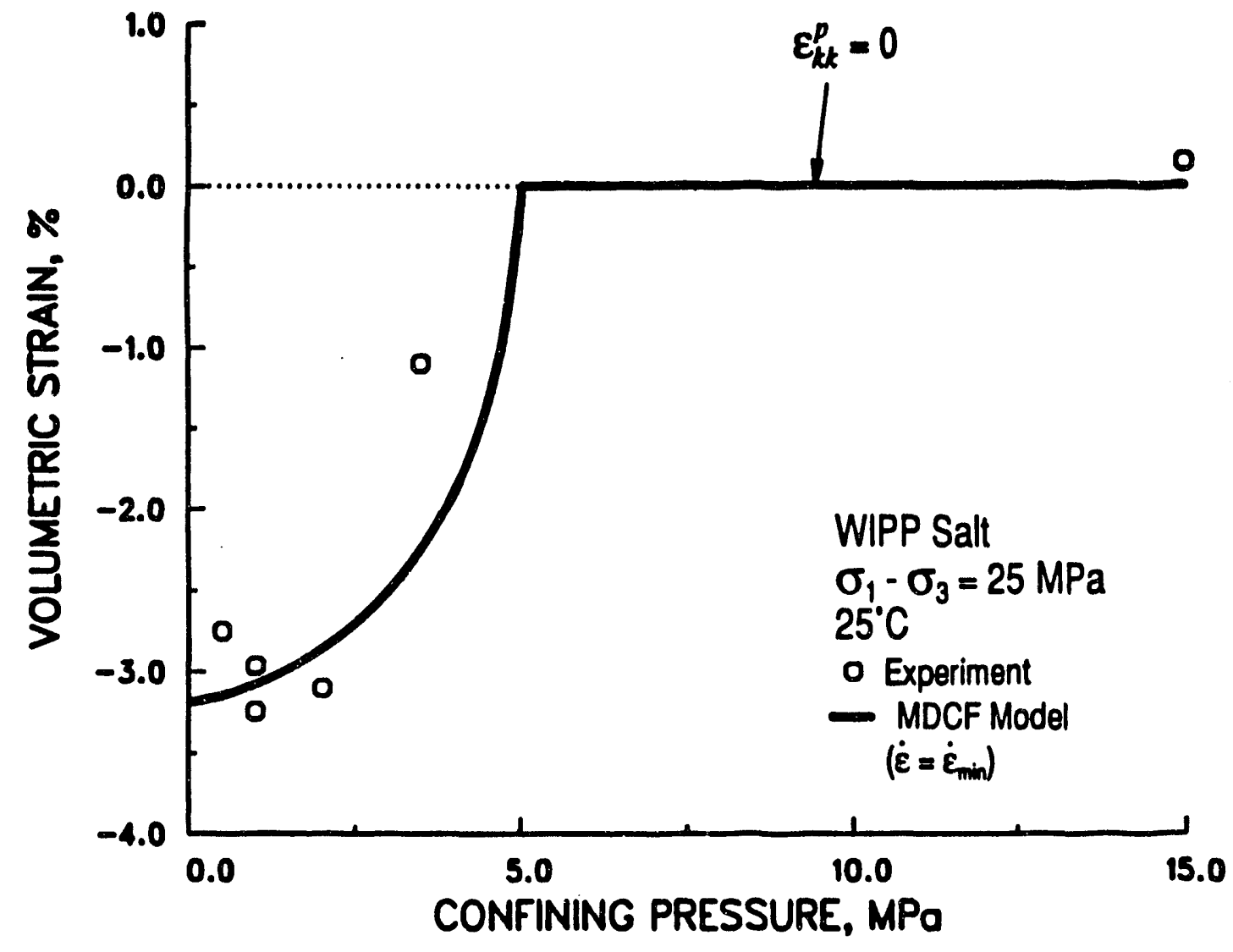

Figure 4. Measured and calculated volumetric strains for creep of WIPP salt tested at $\sigma_{1}-\sigma_{3}=25 \mathrm{MPa}$ under various confining pressur:s. The volumetric strains were obtained at the time when the minimum strain (creep) rate was observed. 


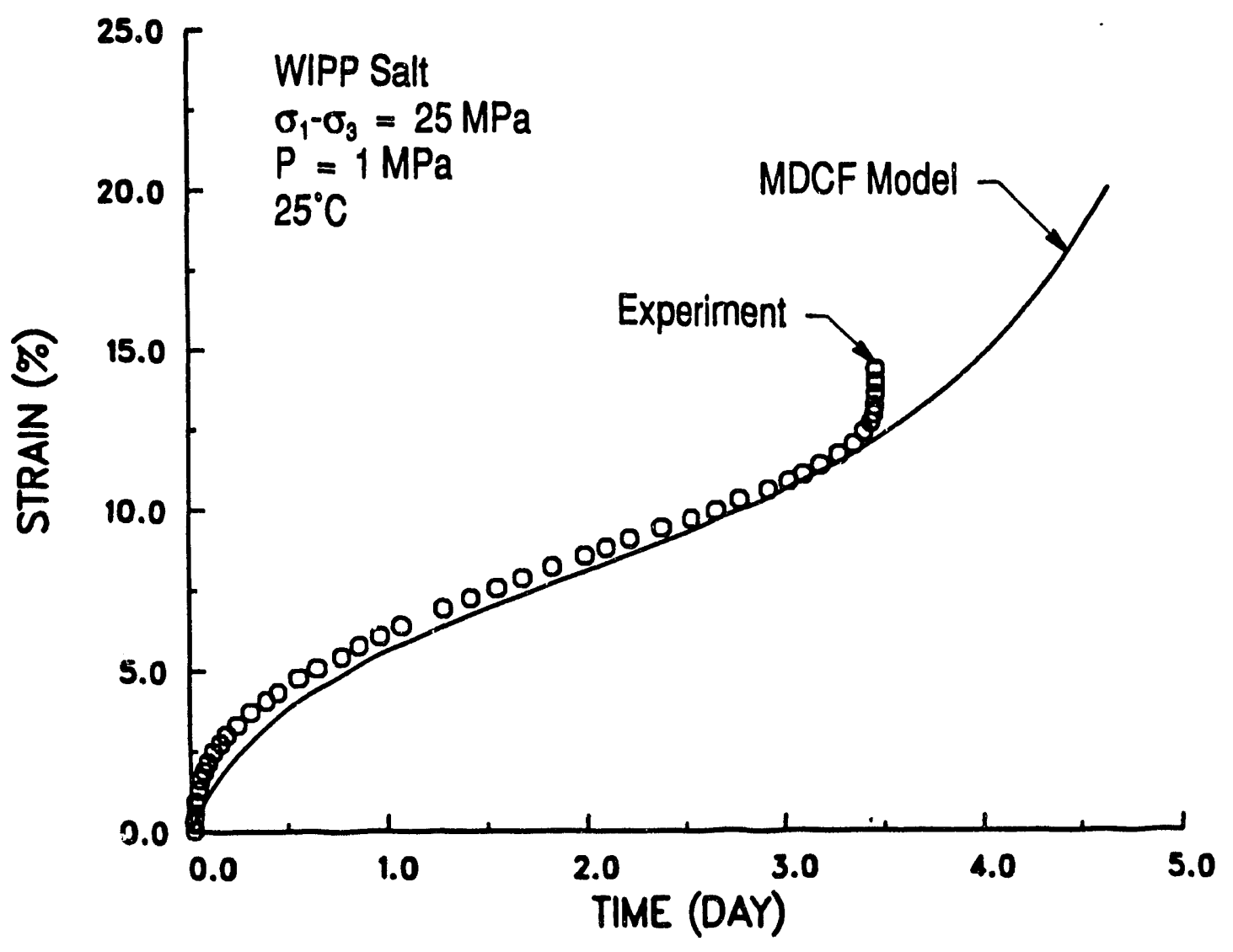

Figure 5. Comparison of calculated and experimental creep curves for WIPP salt tested at a stress difference of $25 \mathrm{MPa}$ and $1 \mathrm{MPa}$ confining pressure. 


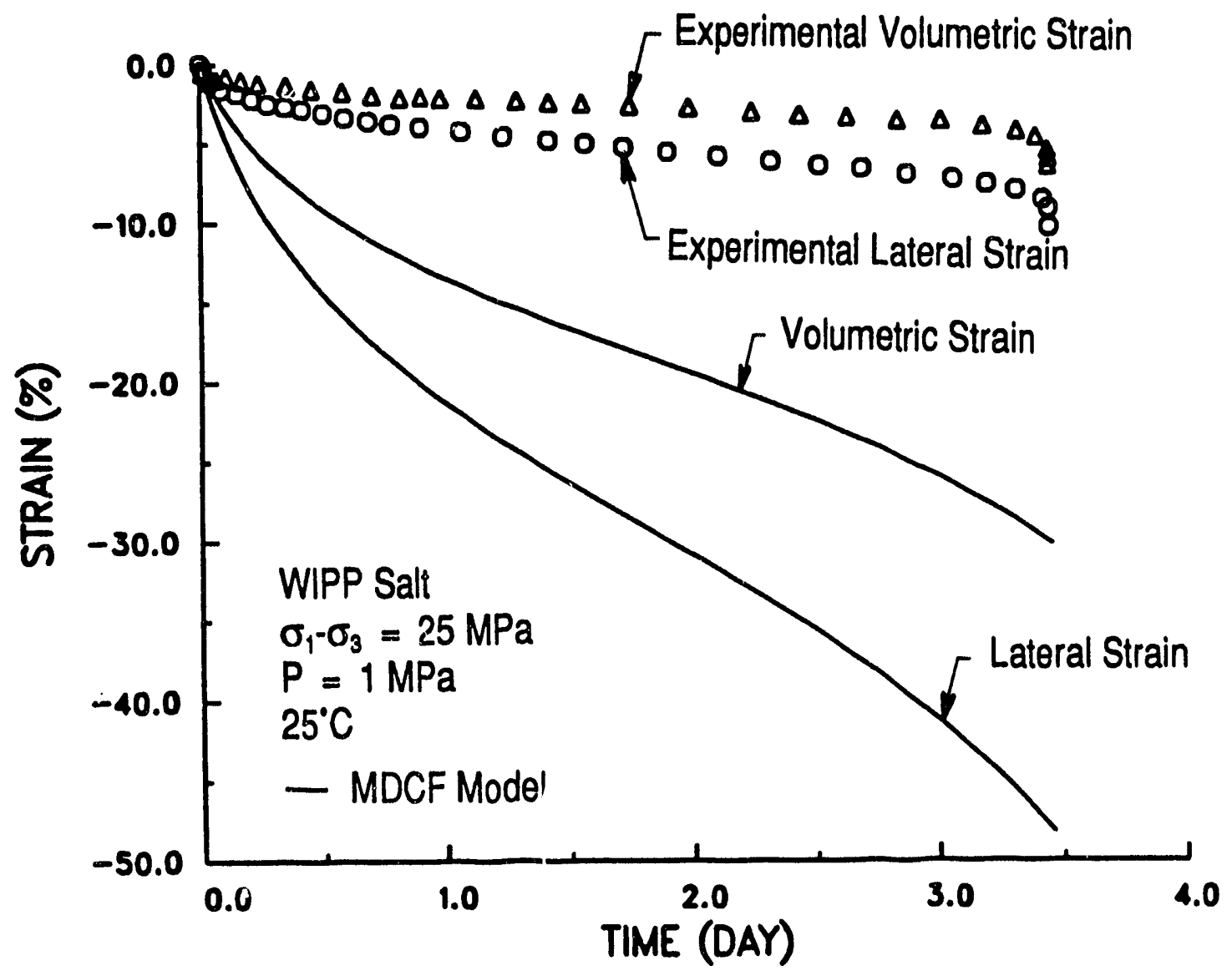

Figure 6. Comparison of calculated and experimental lateral and volumetric strains for WIPP salt crept at a stress difference of $25 \mathrm{MPa}$ and $1 \mathrm{MPa}$ confining pressure. Calculation is based on the associated flow law. 


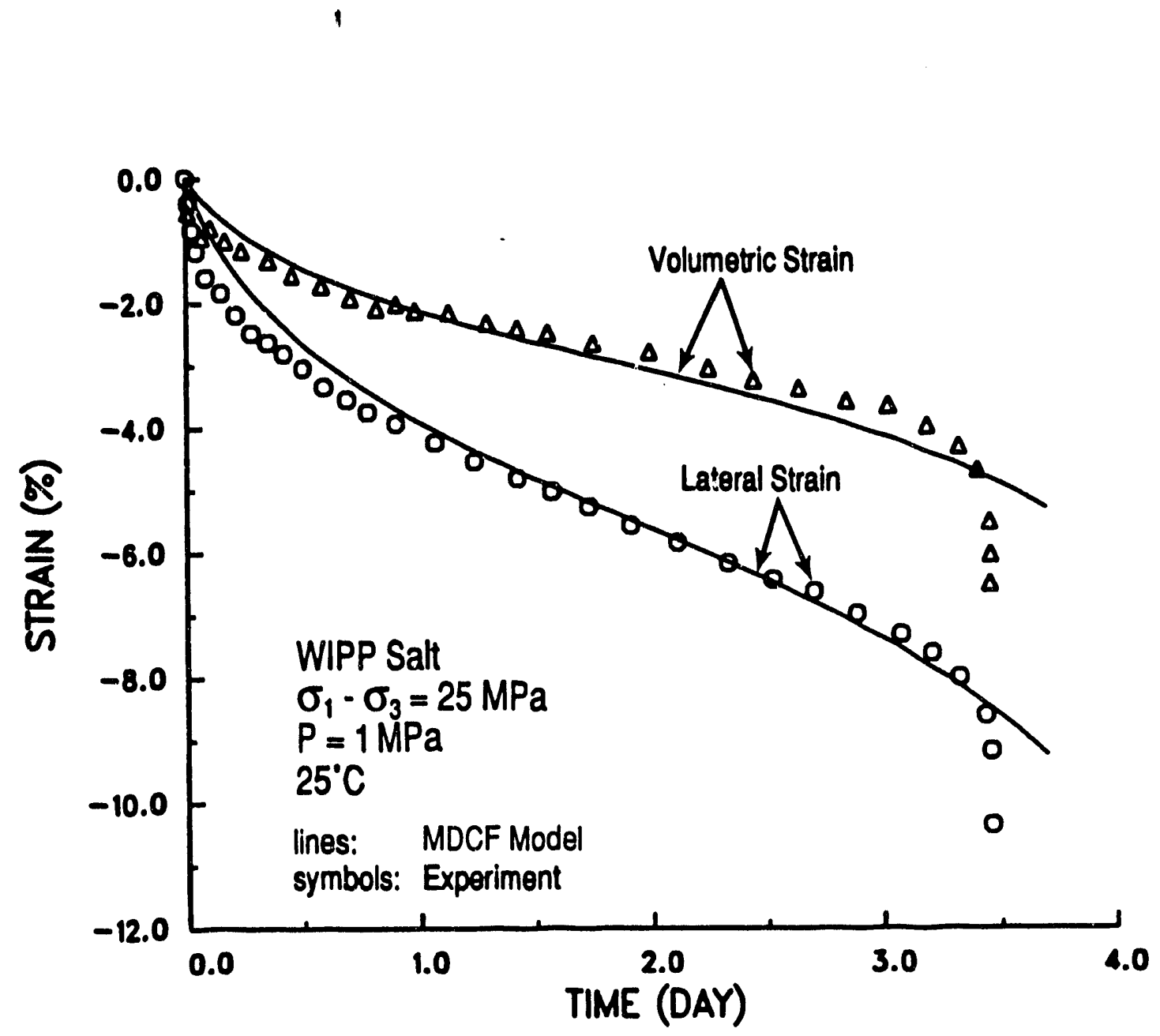

Figure 7. Comparison of calculated and experimental lateral and volumetric strains for WIPP salt crept at a stress difference of $25 \mathrm{MPa}$ and $1 \mathrm{MPa}$ confining pressure. Calculation is based on the nonassociated flow law. 


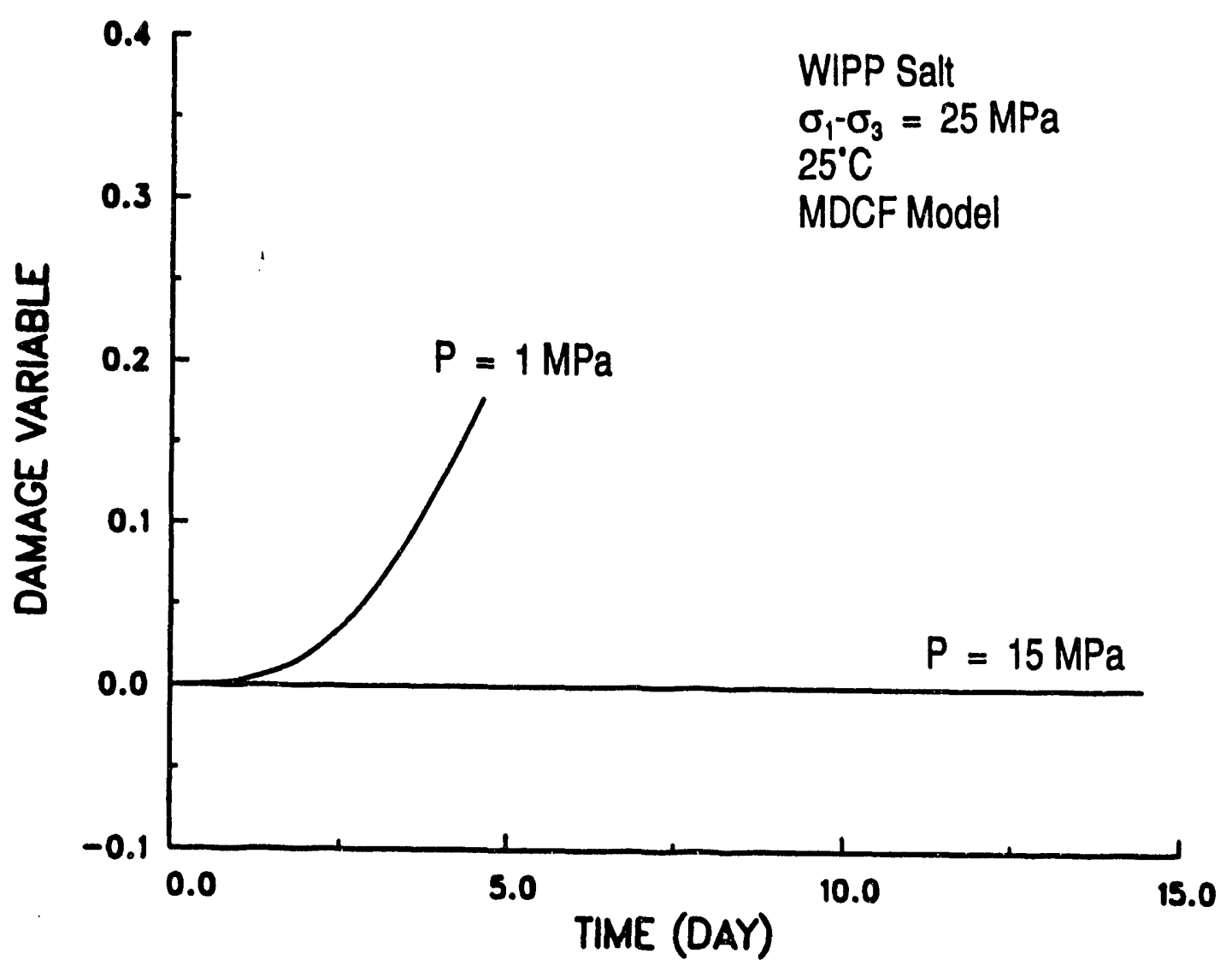

Figure 8. Values of the damage variable, $\omega$, corresponding to the creep curves shown in Figure 1. 


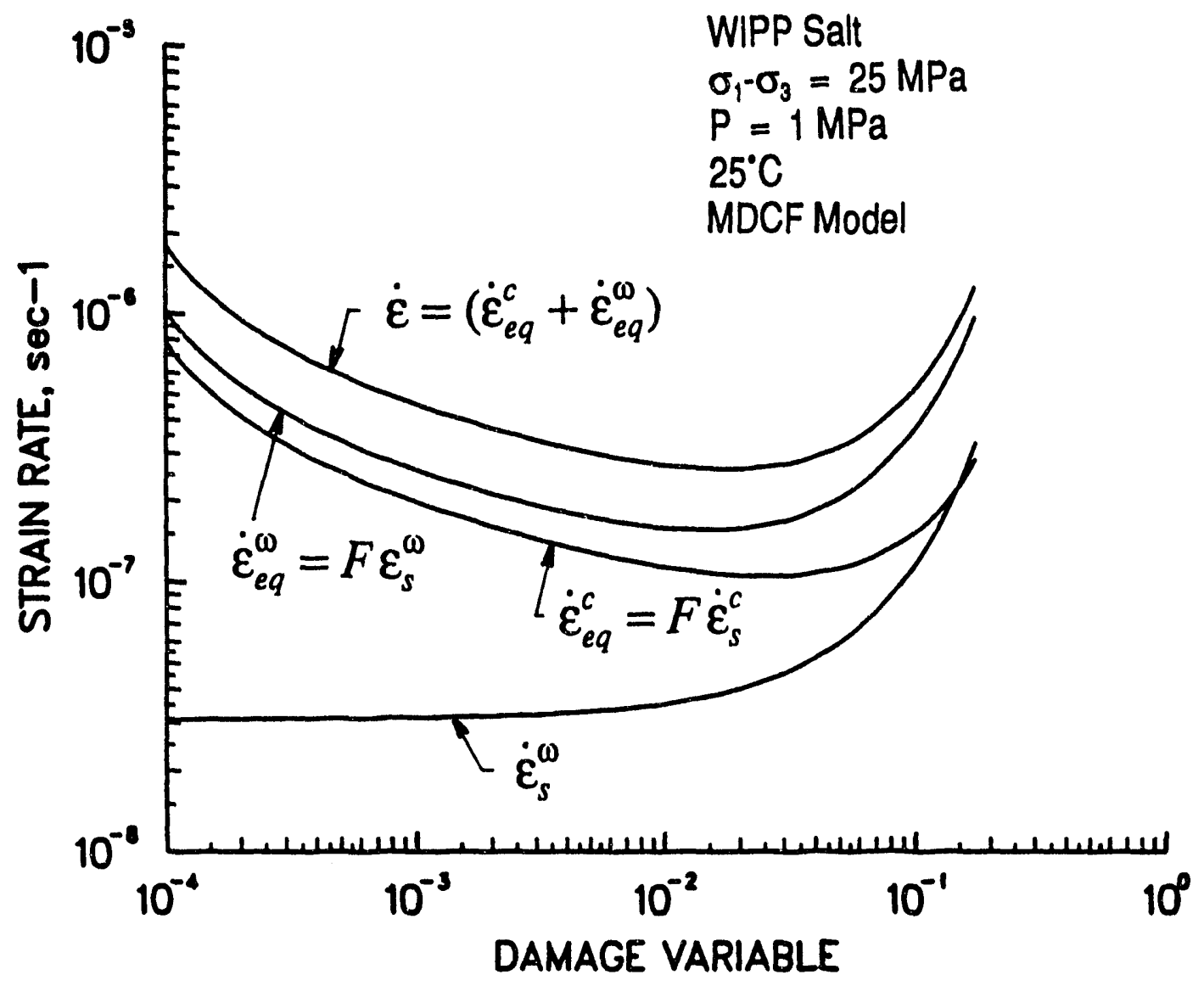

Figure 9. Comparison of the creep rate $\left(\dot{\varepsilon}_{e q}^{c}\right)$ and damaged-induced inelastic strain rate $\left(\dot{\varepsilon}_{e q}^{\omega}\right)$ to the macroscopic strain rate $(\dot{\varepsilon})$ showing $\dot{\varepsilon}_{e q}^{\omega}$ is a significant portion of the macroscopic strain rate. 


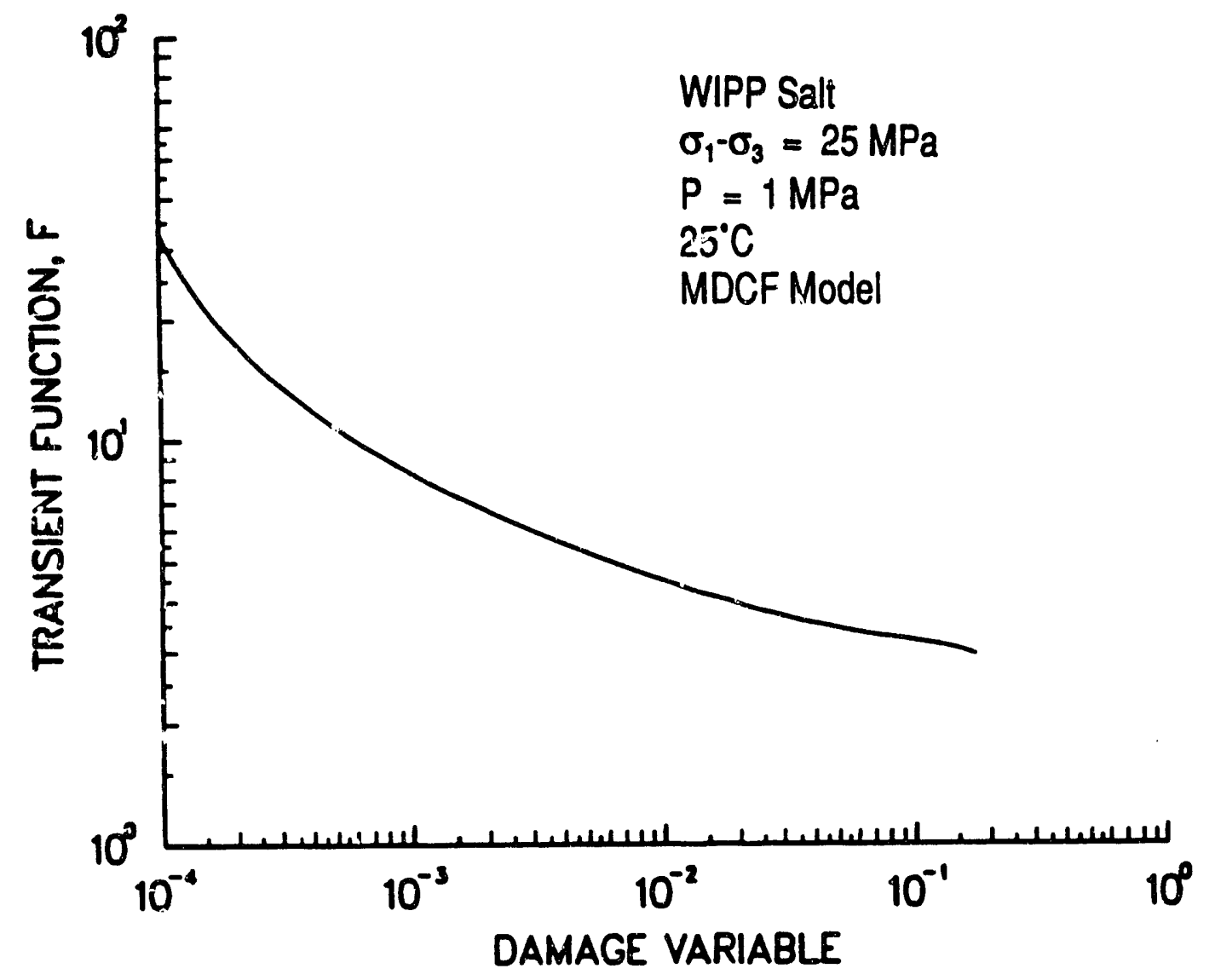

Figure 10. Values of the transient function, $F$, as a function of the damage variable. 

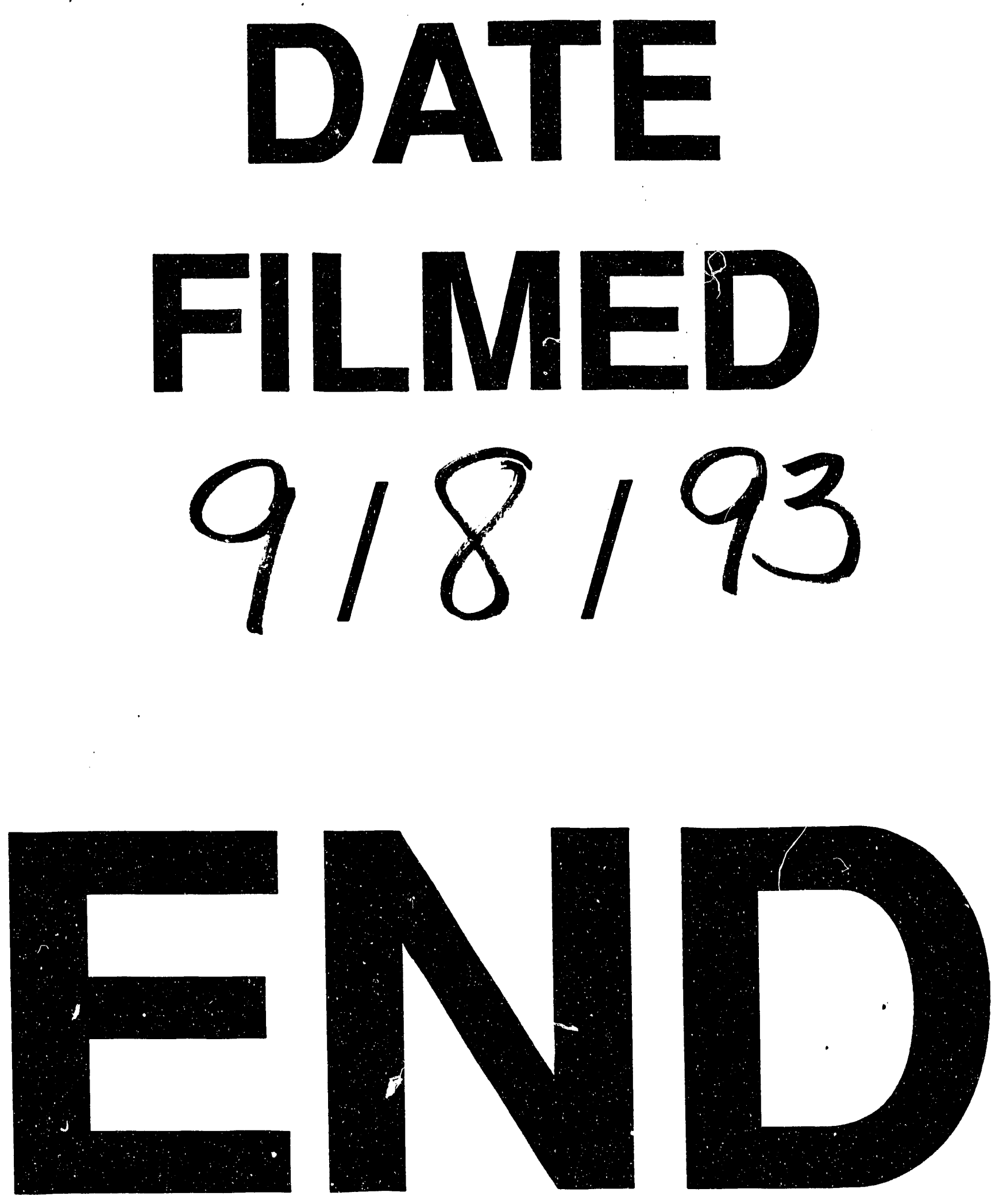
